\title{
Time use, emotional well-being and unemployment: Evidence from longitudinal data
}

\author{
Alan B. Krueger \\ CEA, Woodrow Wilson School and Economics Dept., Princeton University \\ Andreas Mueller \\ Columbia University
}

First draft: December 17, 2011

This draft: January 1, 2012

\begin{abstract}
This paper provides new evidence on the time use and emotional well-being of unemployed individuals in the weeks before and after starting a new job. The major findings are: (1) time spent on home production drops sharply at the time of re-employment, even when controlling for individual fixed effects; (2) time spent on leisure-related activities, which the unemployed find less enjoyable, drops on re-employment, but less so when controlling for individual fixed effects; (3) the unemployed report higher levels of sadness during specific episodes of the day than the employed; and (4) sadness decreases abruptly at the time of reemployment.
\end{abstract}


How do unemployed individuals allocate and experience their time? How does their time use and emotional experience change once they find a job? This paper provides new evidence on the time use and emotional well-being of unemployed and employed individuals in the U.S., using longitudinal data from a survey of unemployed workers in New Jersey. We find evidence that the time spent on home production activities drops sharply at the time of re-employment, with the magnitude of the shift in line with previous research using cross-sectional time use surveys (Hamermesh and Burda, 2010; Krueger and Mueller, forthcoming). ${ }^{1}$ Leisure activities also decrease at the time of re-employment, though somewhat less than in cross-sectional time use data, partly because those finding a job were spending more time on job search activities in the weeks prior to re-employment.

We also investigate the relationship between unemployment and emotional well-being in connection with time use. Despite the fact that the unemployed spend relatively more time in leisure-related activities, we find that the unemployed enjoy these activities to a lesser degree than their employed counterparts and thus, on an average day, report higher levels of sadness than the employed. Moreover, using the longitudinal data from the NJ survey, we find that the sadness decreases significantly at the time of re-employment.

\section{Data}

We use data from the Survey of Unemployed Workers in New Jersey, where a group of 6,025 unemployed workers was interviewed each week for a period of up to 12 weeks from midOctober 2009 to mid-January 2010, and the long-term unemployed were surveyed for an additional 12 weeks, with interviewing ending in mid-April 2010. The respondents were invited

\footnotetext{
${ }^{1}$ Taskin (2010) reaches a similar conclusion analyzing data from the Panel Study of Income Dynamics (PSID) from 1979 to 1986 based on weekly self-reported hours of housework.
} 
each week to participate even if they had already found a job, which makes it possible to analyze their responses before and after re-employment. The survey was web-based and included a time diary, where respondents had to report their time use on the previous day and select for each hour of the day between 7 a.m. to 11 p.m. one or two activities from a list of 21 activities, comparable to the most frequently reported activities in the American Time Use Survey (ATUS). The Appendix in Krueger and Mueller (2011) describes the survey design and the data in more detail. We also use data from the ATUS 2009-10.

The main focus of this paper is to analyze the differences in time use and emotional wellbeing between employed and unemployed individuals. We follow Krueger and Mueller (2011) and define as unemployed those who have not yet accepted a job and have not been working for pay in the reference week. The definition of employment in the NJ survey is somewhat difficult as workers in New Jersey may work part-time and still be eligible for Unemployment Insurance (UI) benefits. ${ }^{2}$ Indeed, around 11 percent of the UI recipients in our sample report that they were working for pay at least one hour in the previous week but had not accepted a job during the survey period. For this reason, it was difficult to establish whether and at what time unemployed workers started working on a part-time job and thus, we restrict our sample of employed individuals to those who accepted a full-time job (i.e., working more than 32 hours per week) in the sample period. We infer the start date of the new job from administrative UI data based on the last week of UI benefit payment if the unemployed worker exited UI before exhausting benefits (we refer to this further below as “early UI exit”). ${ }^{3}$ Because we want to avoid potential mis-classifications, we exclude all observations where the respondent reported working for pay

\footnotetext{
${ }^{2}$ Earnings are deducted from the UI benefit, with an earnings disregard of 20 percent of the weekly UI benefit.

${ }^{3}$ Note that we exclude the week in which the person exited the job, since it is not clear if the respondent started the job in the same week or the week after. Figure 1 shows that this assumption is justified as the time spent working in week 0 is exactly in between the time spent working before and after that.
} 
in the previous week but had not yet accepted a full-time job and observations where the respondent reported that he or she had a accepted a job before the start of the survey, but we did not have information on whether the job was part- or full-time. Note also that we restrict the sample to individuals aged 20 to 65 and limit responses to weekdays. ${ }^{4}$ Our total sample size is 4,465 unemployed workers (22,087 diary days), of whom 271 accepted a full-time job during the sample period and exited UI early. ${ }^{5}$ We also report the results with less restrictive sample criteria and find that our main results are robust to these alternative specifications.

\section{Home production and leisure before and after re-employment}

Columns 1-3 of Panel A in Table 1 show the average minutes of time spent in different activities in the ATUS. As in the NJ survey, we restrict the employed to those who are employed full-time and the unemployed to those who are eligible for UI benefits, because the ATUS lacks data on UI benefit receipt ${ }^{6}$, and we exclude weekend days and the hours in the time diary before 7 a.m. and after 11 p.m. ${ }^{7}$ Comparing the average minutes spent in different activities in the ATUS to the estimates from the NJ survey in Columns 4-6, we find that they match the differences in time use between the employed and unemployed individuals surprisingly well. Most importantly, time spent working differs by just 13 minutes, and thus we are confident that our measure of employment captures the start date of the job well. The estimates from the NJ

\footnotetext{
${ }^{4}$ Participants were invited for the online interview from Tuesday to Saturday to evenly represent all weekdays in the time diary (which covered the previous day). The survey allowed for interviews on Sunday and Monday, but we exclude these observations because of potential selection issues (especially for those who started a new job).

${ }^{5}$ We find a weekly job finding rate of around one percent. This is in line with the rate of early UI exits from midOctober 2009 to mid-March 2010, as reported in Table 12 in Krueger and Mueller (2011).

${ }^{6}$ See Krueger and Mueller (2010) for details.

${ }^{7}$ Using data for the full 24 hours of the day we find that the differences in time use between the employed and unemployed are very similar. The only exceptions are sleeping and work, where the differences in time spent between the employed and unemployed are -71 and 430 minutes instead of -32 and 401 minutes (as reported in Table 1). This suggests that - except for sleeping and work - differences in time use between the two groups arise mainly during the time of the day covered by the NJ survey.
} 
survey suggest a larger employment-unemployment gap in time use for childcare and computer use and a smaller gap for watching TV than in the ATUS. Some of these discrepancies probably arise because of differences in the survey mode. ${ }^{8}$ An additional reason for the difference could be that our survey participants were more likely to use a computer in their leisure time than watch TV. It is important, however, to highlight that when we aggregate time use into a broad measure of leisure (sleep, personal care, eating, leisure and socializing and email/internet/computer use) and home production (cooking/housework, care of others and shopping), we find the differences between the two surveys in the employment-unemployment gap in time spent are relatively small (29 minutes per weekday for the broad measure of leisure and just 1 minute for home production).

The main advantage of the NJ survey is that it enables us to control for individual fixed effects. The results in Column 7 of Table 1 show that including individual fixed effects matter very little for the differences in the time spent on home production (135 instead of 126 minutes per weekday). The employment-unemployment gap in time spent on leisure, however, is much smaller in the fixed effect estimation (122 instead of 222 minutes per weekday for the broad measure). The counterpart for the smaller change in leisure time at the time of re-employment is a larger difference in time spent on job search and travel, which indicates that those searching (and travelling) more are more likely to leave unemployment. Note, however, that this selection effect is specific to the re-employment margin, as the time spent on job search should affect the probability of exiting from unemployment, but not the probability of entering unemployment.

\footnotetext{
${ }^{8}$ The ATUS only records primary activities, whereas in the NJ survey respondents were given the opportunity to record up to two activities for each hour, which left it open whether these activities were exercised sequentially or simultaneously. When two activities were reported in a given hour, we allocate 30 minutes to each one of these activities. This might explain why the unemployed in the NJ survey spend more time on care of others, as this is often a secondary activity. It might also explain the lower amount of time spent in watching TV, as watching TV is often exercised simultaneously with another activity. When we count all episodes of TV watching as 60 minutes, independently of whether a second activity was reported or not, we find that the difference in watching TV between the employed and unemployed is 73 minutes, which is much closer to the ATUS estimate.
} 
Table 1. Difference in time use and emotions between the employed $(E)$ and unemployed (U), by time use category

\begin{tabular}{|c|c|c|c|c|c|c|c|}
\hline \multirow[b]{2}{*}{$\begin{array}{l}\text { Panel A: Time use, by activity, } \\
\text { in minutes per weekday }\end{array}$} & \multicolumn{3}{|c|}{$\begin{array}{c}\text { ATUS } \\
\text { (weekdays, } 7 \mathrm{am}-11 \mathrm{pm} \text {, } \\
\text { 2009-10) }\end{array}$} & \multicolumn{3}{|c|}{$\begin{array}{c}\text { NJ survey } \\
\text { (weekdays, pooled } \\
\text { cross-section) }\end{array}$} & \multirow{2}{*}{$\begin{array}{c}\text { NJ survey } \\
\text { (removing } \\
\text { individual } \\
\text { fixed effects) } \\
\text { E - U }\end{array}$} \\
\hline & $\mathbf{E}$ & $\mathbf{U}$ & $\mathbf{E}-\mathbf{U}$ & $\mathbf{E}$ & $\mathbf{U}$ & $\mathbf{E}-\mathbf{U}$ & \\
\hline Sleep & 88 & 120 & $-32 * * *$ & 57 & 102 & $-45 * * *$ & $-31 *$ \\
\hline Personal Care & 28 & 28 & 0 & 34 & 40 & -6 & 2 \\
\hline Eating & 60 & 57 & 3 & 70 & 72 & -1 & $14 * *$ \\
\hline Work & 412 & 11 & $401 * * *$ & 395 & 8 & $388 * * *$ & $391 * * *$ \\
\hline of which: other income generating act. & 1 & 6 & -5 & n.a. & n.a. & n.a. & n.a. \\
\hline Job search & 0 & 56 & $-55 * * *$ & 5 & 70 & $-65 * * *$ & $-101 * * *$ \\
\hline Education & 4 & 22 & $-18 * * *$ & 8 & 32 & $-24 * * *$ & $-20 * *$ \\
\hline Cooking/housework & 62 & 147 & $-85 * * *$ & 46 & 111 & $-65 * * *$ & $-74 * * *$ \\
\hline Care of others & 26 & 59 & $-34 * * *$ & 28 & 81 & $-53 * * *$ & $-54 * * *$ \\
\hline $\begin{array}{l}\text { of which: care of household children } \\
\text { of which: care of other household members }\end{array}$ & $\begin{array}{c}21 \\
1\end{array}$ & $\begin{array}{c}39 \\
4\end{array}$ & $\begin{array}{c}-18 * * * \\
-3 * *\end{array}$ & 26 & 74 & $-48 * * *$ & $-42 * * *$ \\
\hline Shopping & 15 & 23 & $-8 * * *$ & 9 & 17 & $-9 * * *$ & -7 \\
\hline Services & 5 & 8 & $-3 * *$ & n.a. & n.a. & n.a. & n.a. \\
\hline Leisure and socializing & 165 & 320 & $-155 * * *$ & 129 & 245 & $-115 * * *$ & $-65 * * *$ \\
\hline of which: TV & 98 & 190 & $-92 * * *$ & 58 & 110 & $-52 * * *$ & $-50 * * *$ \\
\hline of which: reading/writing & 9 & 14 & -5 & 9 & 26 & $-17 * * *$ & $-9 * *$ \\
\hline of which: exercising & 12 & 21 & $-9 * *$ & 8 & 17 & $-10 * * *$ & $-12 *$ \\
\hline Email/Internet/Computer use & 8 & 17 & $-9 * * *$ & 30 & 84 & $-54 * * *$ & $-38 * * *$ \\
\hline Volunteer, religious and civic act. & 8 & 12 & -3 & n.a. & n.a. & n.a. & n.a. \\
\hline Commuting/Travel & 71 & 55 & $16 * * *$ & 108 & 40 & $68 * * *$ & 48 \\
\hline \multirow[t]{2}{*}{ Other } & 9 & 27 & $-17 * * *$ & 39 & 58 & -19 & -65 \\
\hline & \multicolumn{3}{|c|}{ (year 2010) } & & & & \\
\hline $\begin{array}{l}\text { Panel B: Emotions }(0=\text { not at all; } \\
6=\text { extremely strong) }\end{array}$ & $\mathbf{E}$ & $\mathbf{U}$ & $\mathbf{E}-\mathbf{U}$ & $\mathbf{E}$ & $\mathbf{U}$ & $\mathbf{E}-\mathbf{U}$ & $\mathbf{E}-\mathbf{U}$ \\
\hline Happy & 4.06 & 3.97 & 0.09 & 3.67 & 3.24 & 0.43 & $0.95 *$ \\
\hline Sad & 0.63 & 1.12 & $-0.49 * * *$ & 0.70 & 1.34 & $-0.65 * * *$ & $-0.61 * * *$ \\
\hline Stressed & 1.93 & 1.98 & -0.05 & 1.35 & 1.89 & $-0.54 * * *$ & $-0.64 *$ \\
\hline Pain & 0.76 & 1.36 & $-0.60 * * *$ & n.a. & n.a. & n.a. & n.a. \\
\hline Tired & 2.44 & 1.99 & $0.45 * * *$ & n.a. & n.a. & n.a. & n.a. \\
\hline Meaningful & 4.37 & 4.34 & 0.03 & n.a. & n.a. & n.a. & n.a. \\
\hline
\end{tabular}


Figure 1. Time spent on working, home production and leisure activities, in minutes per weekday, before and after re-employment
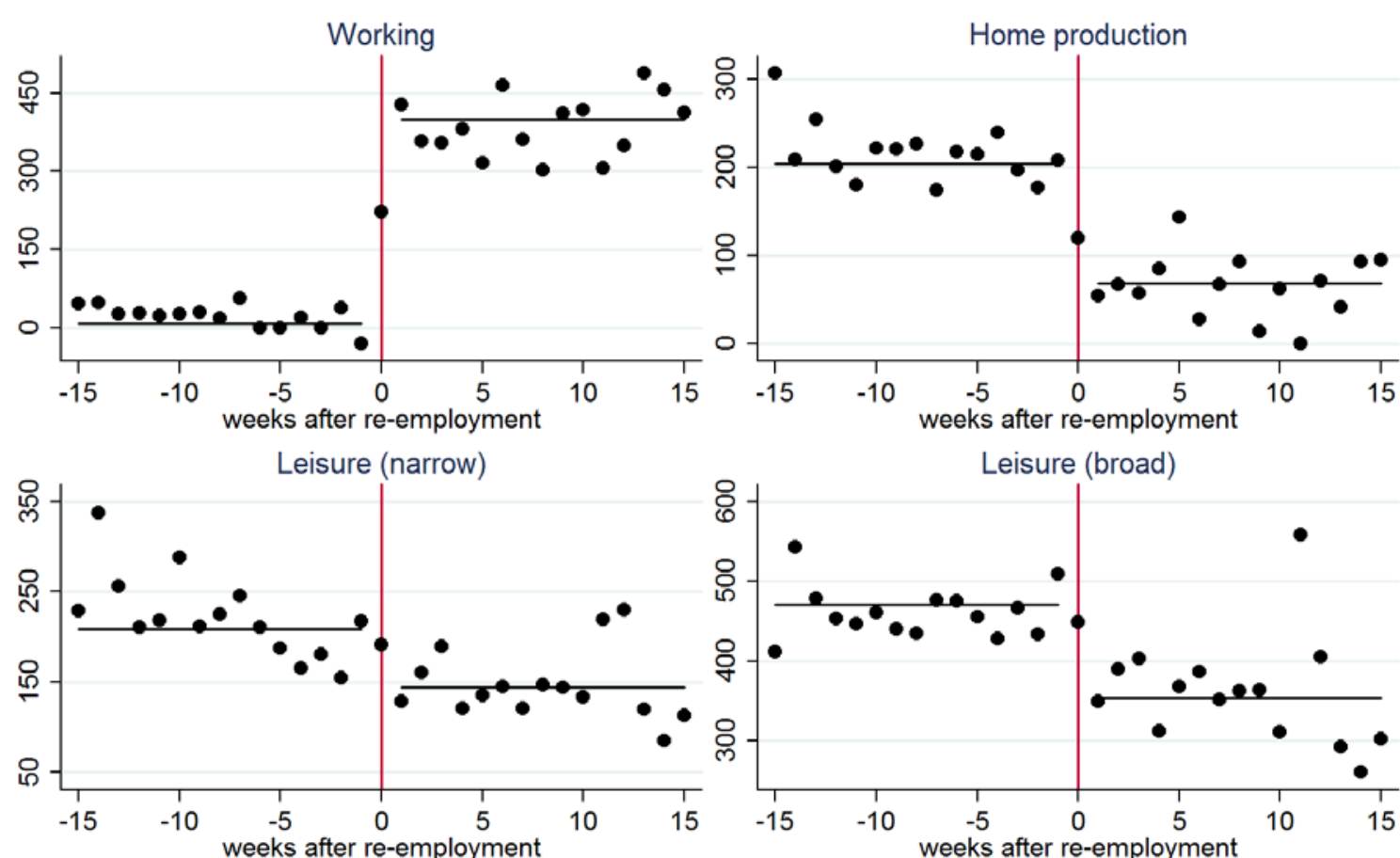

Notes: The solid lines show the average time use before and after re-employment, whereas the dots show the estimates for each week. Individual fixed effects are removed from all estimates in the figure (i.e., the dots and the lines).

Home production activities are defined as: food preparation, shopping, housework, care for family and non-family members.

Leisure activities are defined as: sleeping, resting/relaxing $(n)$, watching TV $(n)$, reading/writing (n), personal care, eating/drinking,

socializing $(n)$, exercising $(n)$, on the phone $(n)$ and email/internet/computer use, where $(n)$ indicates that the activity is included in the

narrow definition of leisure. Sample: no job yet accepted at the start of survey; age 20-65.

Figure 1 also shows the time use in the weeks before and after re-employment, removing individual fixed effects. Time spent on work jumps up discretely at the time of re-employment, which suggests that we capture well the start date of the new job. At the same time, home production and leisure drop sharply at the time of re-employment, in line with the numbers presented in Table 1. The figure also suggests that the time spent on home production does not change much over the spell of unemployment, as there is no clear trend in the weeks before reemployment. To investigate this further, we regressed the time spent on home production activities on the duration of unemployment and individual fixed effects. We find a negative and insignificant coefficient on the duration of unemployment. This suggests that the unemployed 
have passed the point of diminishing marginal productivity in activities such as cooking, housework and childcare already at the beginning of the spell of unemployment.

It is useful to express the change in time spent on home production and leisure as a percentage of the change in the time spent on working time: the increase in the time spent on home production at the time of re-employment is around 35 percent of the change in the time spent on work, and the same number for leisure is 31 percent.

As a robustness check, we use as an alternative measure of the employment status a question in the survey which asked the respondent whether he or she was working for pay for at least one hour during the past week. This definition should include transitions from unemployment to both part-time and full-time jobs. Controlling for individual fixed effects, we find that the increase in time spent on working is 123 minutes compared to 388 minutes above, which confirms the observation above that part-time work is wide-spread among the UI recipients in NJ. Note, however, that when we compute the change in home production and leisure time as percentage of the change in working time, we find that time spent in home production increases by 29 percent and time spent in leisure increases by 53 percent (both effects are significant at the 1 percent level). This suggests some non-linearity in the change of leisure at the time of re-employment, as with smaller changes in time spent on market work, time spent on leisure time increases more in percentage of the change time spent working. An additional reason for the difference in the estimate might be that, with this measure of employment, we also observe transitions from employment to unemployment, as some indicated working for pay in a given week but not in subsequent weeks. 


\section{Emotional well-being before and after re-employment}

With data from the NJ survey and data from the well-being module of the ATUS 2010, we can evaluate how the subjective well-being differs between employed and unemployed individuals in connection with their time use. ${ }^{9}$ Both surveys randomly sampled three episodes in the time diary and asked the participants to rate their emotions during that episode on a scale from 0 to $6^{10}$, where 0 means that the person did not experience that feeling at all and 6 means that the feeling was extremely strong. Both surveys asked the respondents to rate their feelings happy, sad and stressed and the well-being module of the ATUS asked in addition the emotions in pain, tired and meaningful.

Table 2. Difference in the emotion sad between the employed (E) and unemployed (U), by time use category

\begin{tabular}{|c|c|c|c|}
\hline The emotion sad ( $0=$ not at all; $6=$ =xtremely strong) & $\mathbf{E}$ & $\mathbf{U}$ & $\mathbf{E}-\mathbf{U}$ \\
\hline Personal Care & 2.32 & 2.85 & -0.53 \\
\hline Eating & 0.42 & 0.52 & -0.10 \\
\hline Work & 0.72 & 0.00 & $0.72 * * *$ \\
\hline of which: other income generating act. & 0.15 & 0.00 & $0.15^{*}$ \\
\hline Job search & 2.51 & 1.97 & 0.55 \\
\hline Education & 0.99 & 0.63 & 0.35 \\
\hline Cooking/housework & 0.53 & 0.69 & -0.16 \\
\hline Care of others & 0.30 & 1.28 & $-0.97 *$ \\
\hline of which: care of household children & 0.27 & 0.45 & -0.18 \\
\hline of which: care of other household members & 0.73 & 0.00 & $0.73 *$ \\
\hline Shopping & 0.39 & 1.26 & $-0.87 * *$ \\
\hline Services & 1.01 & 3.91 & $-2.90 * *$ \\
\hline Leisure and socializing & 0.55 & 1.02 & $-0.47 * * *$ \\
\hline of which: TV & 0.63 & 1.01 & $-0.38^{*}$ \\
\hline of which: reading/writing & 0.41 & 1.41 & $-1.00 * *$ \\
\hline of which: exercising & 0.38 & 0.84 & -0.46 \\
\hline Email/Internet/Computer use & 0.58 & 0.40 & 0.18 \\
\hline Volunteer, religious and civic act. & 0.69 & 0.94 & -0.25 \\
\hline Commuting/Travel & 0.57 & 0.99 & $-0.42 * * *$ \\
\hline Other & 0.65 & 0.23 & $0.41 * *$ \\
\hline Total & 0.61 & 0.93 & $-0.32 * * *$ \\
\hline
\end{tabular}

Source: The authors' estimates with the ATUS well-being module 2010. Note: We used the ATUS labor force recode to define employment status and thus, included the UI ineligibile job seekers in the unemployed and part-time employees in the employed.

\footnotetext{
${ }^{9}$ See the webpage http://www.krueger.princeton.edu/data/ATUS/ATUSWellbeingFiles.html for details on the wellbeing module of the ATUS 2010.

${ }^{10}$ In the NJ survey, in addition to the three random episodes, one episode of job search was selected.
} 
Figure 2. The emotion sad ( $0=$ not at all; $6=$ extremely strong), before and after re-employment

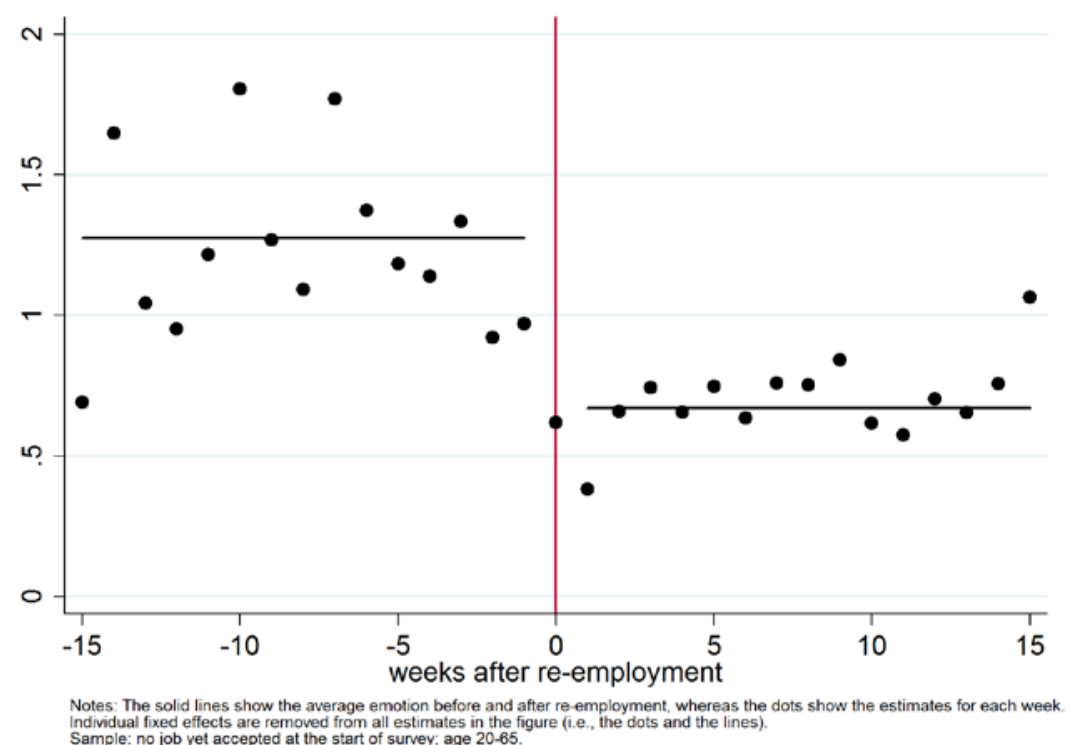

Table 2 shows the average ratings of the emotion sad of the employed and unemployed during specific activities of the day in the ATUS sample ${ }^{11}$. The unemployed are significantly sadder during leisure time, which could be due to the low amount of income the unemployed have to spend on leisure activities, to diminishing marginal utility of leisure or because the unemployed have time to think about their predicament, especially when they are watching TV. ${ }^{12}$ The unemployed also feel sadder when shopping, probably because they are reminded of the many things they can no longer afford to purchase. Interestingly, the unemployed feel much less sad when they engage in work activities, which are mostly income generating activities such as hobbies and musical performances. These work-related activities, however, absorb a very small share of the average day of the unemployed.

Panel B of Table 1 shows that the average emotions over the course of the entire day. The unemployed in the ATUS express higher levels of sadness and more pain than their employed

\footnotetext{
${ }^{11}$ To increase the sample size, we included those individuals who are not eligible for UI benefits in the unemployed and part-time workers in the employed, and we also included weekend days. See also the online Appendix Table, which shows the results for all emotions during specific episodes of the day.

${ }^{12}$ We report a similar finding in Krueger and Mueller (2008) based on a smaller sample.
} 
counterparts, but also less tiredness. No difference is found for the emotions happy and stressed. This might explain why Knabe et al. (2010), based on a survey of long-term unemployed in Germany, find no differences in emotional well-being between the employed and unemployed, because they did not include emotions such as sad and in pain in their survey. We find similar results in Columns 4-6, which report the same statistics for the NJ survey, with the exception that the employed in NJ appear more stressed. The fixed effects estimates yield similar results, but the difference in happiness becomes significant at the 10 percent level. Note that some of these effects could be of temporary nature, as the first couple of weeks and months back to work might be a big relieve from the stress and anxiety related to the experience of unemployment and job search. This is, however, unlikely to be true for the effect of unemployment on sadness, because it holds both in the NJ survey as well as the ATUS, which covers a representative sample of employed and not just those who recently became re-employed. This conclusion is also supported by Figure 2, which shows no clear trend in sadness over the 15 weeks after reemployment. One open question remains whether emotional well-being increases instantly to the pre-unemployment level or whether there are permanent scarring effects as found in studies of panel data of global evaluations of subjective well-being (Clark et al., 2008).

We also computed the corresponding statistics for a different definition of employment (working for pay for at least one hour in the past week) with the NJ survey. We find that the employed tend to be happier (by 0.25 points), less sad (by 0.29 points) and less stressed (by 0.15 points $)^{13}$. The smaller coefficients, however, suggest that the biggest gains in emotional wellbeing are concentrated among those who start a full-time job. Finally, we find that the share of those who report being satisfied or very satisfied with life increases by 25 percentage points at the time of starting a full-time job and by 7 percentage points in weeks working for pay for at

\footnotetext{
${ }^{13}$ All these differences are significant at the 1 or 5 percent level.
} 
least one hour (both significant at the 1 percent level), indicating that the changes in emotional well-being align well with changes in global evaluations of subjective well-being.

\section{Conclusions}

We shed new light on the experience of unemployment, by studying diary data on time use and emotional well-being of unemployed workers in the U.S. The novel feature of our analysis is the use panel data before and after the time of re-employment. Controlling for individual fixed effects, we find that the time spent on home production activities, such as cooking, housework, childcare and shopping, drops sharply at re-employment by around 35 percent of the increase in time spent working. This is consistent with previous research based on cross-sectional time use data.

Aguiar et al. (2011) also show that around 30 to 40 percent of foregone market hours in recessions are allocated to home production activities. These numbers are similar to the drop in the time spent on home production activities at re-employment and thus, transitions from unemployment to employment (and vice versa) should lead to changes in the time use of the population as a whole, which are consistent with Aguiar et al.. To gauge the importance of such transitions for changes in aggregate time use, consider the increase in the unemployment rate of 5.7 percentage points in the recent recession (from trough to peak). If the difference in time spent on home production between the employed and unemployed stayed constant over that period, this increase in the unemployment rate would generate a drop in home production hours of around half an hour per week, which is more than half the increase in home production relative ${ }^{14}$

\footnotetext{
${ }^{14}$ Aguiar et al. (2011) estimate that 36.8 percent of foregone market hours are allocated to home production activities (including childcare). They also report that market hours fell by 2.1 hours between 2007/08 and 2009/10, which implies that home production activities increased by 0.77 hours per week relative to trend over that period.
} 
to trend in the recent recession. This suggests that fluctuations in aggregate unemployment are an important determinant of the changes in aggregate time use over the business cycle.

Lastly, we find that the unemployed are sadder compared to when they are employed. Our results are robust to the inclusion of individual fixed effects, and sadness drops sharply in the first weeks after re-employment, which is strong evidence against the hypothesis that the saddening effect of unemployment is driven by selection. Instead, unemployment takes an emotional toll, even during leisure-related activities.

\section{References}

Aguiar, M. A., Hurst, E. and Karabarbounis, L., 2011. “Time Use During Recessions.” NBER Working Papers No. 17259.

Burda, M. C. and Hamermesh, D. S., 2010. "Unemployment, market work and household production.” Economics Letters, 107(2), 131-133.

Clark, A. E., Diener, E., Georgellis, Y. and Lucas, R. E., 2008. “Lags And Leads in Life Satisfaction: a Test of the Baseline Hypothesis.” Economic Journal, 118(529), 222-243.

Knabe, A., Rätzel, S., Schöb, R., and Weimann, J., 2010. "Dissatisfied with Life but Having a Good Day: Time-use and Well-being of the Unemployed.” Economic Journal, 120(547), 867889.

Krueger, A. B. and Mueller, A., 2008. “The Lot of the Unemployed: A Time Use Perspective.” IZA Discussion Paper No. 3490.

Krueger, A. B. and Mueller, A., 2010. “Job Search and Unemployment Insurance: New Evidence from Time Use Data.” Journal of Public Economics, 94 (3-4), 298-307.

Krueger, A.B. and Mueller, A., 2011. “Job Search, Emotional Well-Being and Job Finding in a Period of Mass Unemployment: Evidence from High-Frequency Longitudinal Data. ” Brookings Papers on Economic Activity, 42(1), 1-81.

Krueger, A. B. and Mueller, A. “The Lot of the Unemployed: A Time Use Perspective.” Forthcoming in the Journal of the European Economic Association.

Taskin, Temel. 2010. “Unemployment Insurance and Home Production.” European University Institute, mimeo. 
Appendix Table. Emotions during specific episodes of the day, difference between unemployed and employed individuals

\begin{tabular}{|c|c|c|c|c|c|c|c|c|c|c|c|c|c|c|c|c|c|c|}
\hline \multirow{3}{*}{ Time Use Activity } & \multicolumn{18}{|c|}{ Emotions ( $0=$ not at all; $6=$ extremely strong) } \\
\hline & \multicolumn{3}{|c|}{ Happy } & \multicolumn{3}{|c|}{ Sad } & \multicolumn{3}{|c|}{ Stressed } & \multicolumn{3}{|c|}{ Pain } & \multicolumn{3}{|c|}{ Tired } & \multicolumn{3}{|c|}{ Meaningful } \\
\hline & E & $\mathrm{U}$ & $E-U$ & $E$ & $\mathrm{U}$ & $E-U$ & $\mathrm{E}$ & $\mathrm{U}$ & $E-U$ & $E$ & $\mathrm{U}$ & $E-U$ & $\mathrm{E}$ & $\mathrm{U}$ & $E-U$ & $\mathrm{E}$ & $\mathrm{U}$ & $E-U$ \\
\hline Personal Care & 2.43 & 2.61 & -0.19 & 2.32 & 2.85 & 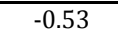 & 3.09 & 2.48 & 0.62 & 4.05 & 3.66 & 0.39 & 3.73 & 4.20 & -0.46 & 3.67 & 4.92 & -1.25 \\
\hline Eating & 4.67 & 4.56 & 0.11 & 0.42 & 0.52 & -0.1 & 1.07 & 1.19 & -0.12 & 0.69 & 0.79 & -0.1 & 2.06 & 1.56 & $0.5^{* * *}$ & 4.55 & 4.55 & 0.01 \\
\hline Work & 3.87 & 5.02 & $-1.15^{* *}$ & 0.72 & 0.00 & $0.72^{* * *}$ & 2.46 & 0.37 & $2.09^{* * *}$ & 0.81 & 4.45 & $-3.63^{* * *}$ & 2.42 & 3.82 & $-1.41^{* *}$ & 4.45 & 5.25 & -0.8 \\
\hline of which: other income generating activities & 4.22 & 5.31 & $-1.10^{*}$ & 0.15 & 0.00 & $0.15^{*}$ & 1.45 & 0.00 & $1.45^{* * *}$ & 0.48 & 5.43 & $-4.95^{* * *}$ & 1.70 & 4.24 & $-2.54^{* * *}$ & 4.38 & 5.83 & $-1.45^{* * *}<x-10$ \\
\hline Job search & 3.84 & 3.58 & 0.26 & 2.51 & 1.97 & 0.55 & 3.68 & 4.04 & -0.36 & 0.67 & 1.14 & -0.47 & 1.38 & 1.83 & -0.45 & 4.52 & 5.11 & -0.59 \\
\hline Education & 3.70 & 3.79 & -0.09 & 0.99 & 0.63 & 0.35 & 2.76 & 2.43 & 0.33 & 0.75 & 0.92 & -0.17 & 3.15 & 1.89 & $1.27 *$ & 5.28 & 5.42 & -0.14 \\
\hline Cooking/housework & 4.07 & 3.72 & $0.35^{*}$ & 0.53 & 0.69 & -0.16 & 1.31 & 1.55 & -0.24 & 0.89 & 1.15 & -0.27 & 2.41 & 1.99 & $0.42^{* *}$ & 4.27 & 4.27 & 0 \\
\hline Care of household and non-household members & 4.81 & 4.76 & 0.05 & 0.30 & 1.28 & $-0.97 *$ & 1.27 & 1.80 & -0.54 & 0.63 & 1.34 & -0.7 & 2.47 & 2.23 & 0.25 & 5.28 & 5.39 & -0.11 \\
\hline $\begin{array}{l}\text { of which: care of household children } \\
\text { of which: care of other household members }\end{array}$ & $\begin{array}{l}4.85 \\
4.50\end{array}$ & $\begin{array}{l}5.10 \\
3.20\end{array}$ & $\begin{array}{r}-0.25 \\
1.3^{*}\end{array}$ & 0.27 & $\begin{array}{l}0.45 \\
0.00\end{array}$ & $\begin{array}{l}-0.18 \\
0.73^{*}\end{array}$ & 1.25 & $\begin{array}{l}1.15 \\
1.47\end{array}$ & 0.1 & 0.53 & 0.59 & -0.06 & 2.52 & 2.08 & 0.44 & 5.38 & 5.20 & 0.18 \\
\hline & & 3.20 & & 020 & & 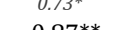 & 1.92 & 1.47 & 0.46 & 0.55 & 0.00 & $0.55^{* *}$ & 2.49 & 1.20 & 1.29 & 5.17 & 3.00 & 2.17 \\
\hline Shopping & 4.35 & 3.45 & 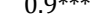 & 0.39 & 1.26 & $-0.87^{* *}$ & 1.51 & 2.17 & -0.66 & 0.64 & 0.73 & -0.09 & 1.98 & 1.28 & $0.71^{* *}$ & 4.04 & 3.85 & 0.19 \\
\hline Services (Personal care, household, ...) & 3.52 & 1.41 & $2.12^{* *}$ & 1.01 & 3.91 & $-2.9^{* *}$ & 2.17 & 5.15 & $-2.98^{* * *}$ & 1.21 & 4.14 & $-2.93^{* * *}$ & 1.92 & 3.93 & $-2.01^{* * *}$ & 4.84 & 4.71 & 0.13 \\
\hline Leisure and socializing & 4.54 & 4.14 & $0.40^{* *}$ & 0.55 & 1.02 & $-0.47^{* * *}$ & 0.97 & 1.23 & $-0.26^{*}$ & 0.76 & 1.17 & -0.41 & 2.33 & 1.70 & $0.64^{* * *}$ & 4.13 & 3.70 & 0.43 \\
\hline of which: TV & 4.33 & 3.88 & $0.45^{* *}$ & 0.63 & 1.01 & $-0.38^{*}$ & 0.93 & 1.41 & $-0.47^{* *}$ & 0.80 & 0.88 & -0.08 & 2.48 & 1.85 & $0.63^{* * *}$ & 3.51 & 3.13 & $0.38^{*}$ \\
\hline of which: reading/writing & 4.26 & 3.17 & $1.09 * * *$ & 0.41 & 1.41 & $-1.00^{* *}$ & 0.94 & 0.47 & 0.47 & 0.54 & 4.14 & $-3.61^{* * *}$ & 2.41 & 2.29 & 0.12 & 4.29 & 1.80 & $2.49^{* *}$ \\
\hline of which: exercising & 4.70 & 3.86 & 0.83 & 0.38 & 0.84 & -0.46 & 0.85 & 0.92 & -0.06 & 1.26 & 1.10 & 0.16 & 2.14 & 1.18 & $0.95^{* *}$ & 4.94 & 3.95 & 0.99 \\
\hline Email/Internet/Computer use & 3.99 & 5.17 & $-1.18^{* * *}$ & 0.58 & 0.40 & 0.18 & 0.99 & 0.75 & 0.25 & 0.54 & 0.40 & 0.15 & 2.36 & 1.01 & $1.34^{* *}$ & 3.44 & 4.58 & -1.14 \\
\hline Volunteer, religious and civic activities & 4.72 & 4.13 & 0.59 & 0.69 & 0.94 & -0.25 & 1.25 & 1.31 & -0.06 & 0.78 & 0.66 & 0.13 & 1.93 & 1.52 & 0.41 & 5.33 & 4.91 & 0.43 \\
\hline Commuting/Travel & 4.25 & 4.16 & 0.09 & 0.57 & 0.99 & $-0.42^{* * *}$ & 1.52 & 1.67 & -0.15 & 0.67 & 0.94 & $-0.28^{* *}$ & 2.35 & 1.85 & $0.5^{* * *}$ & 3.91 & 4.14 & -0.23 \\
\hline Other & 4.55 & 4.49 & 0.07 & 0.65 & 0.23 & $0.41^{* *}$ & 1.86 & 1.42 & 0.43 & 1.00 & 0.62 & 0.38 & 2.45 & 1.15 & $1.3^{* * *}$ & 4.93 & 3.99 & 0.94 \\
\hline All & 4.20 & 4.13 & 0.07 & 0.61 & 0.93 & $-0.32^{* * *}$ & $\mathbf{1 . 7 0}$ & 1.63 & 0.07 & 0.78 & 1.13 & $-0.34^{* * *}$ & 2.35 & 1.81 & $0.54^{* * *}$ & 4.36 & 4.34 & 0.02 \\
\hline
\end{tabular}

Sources: The authors' estimates with the subjective well-being module of the ATUS 2010 . 